\title{
ATTALI (Michaël), CARITEY (Benoît) (dir.), Le SNEP, une histoire en débat
}

Dijon : Éditions universitaires de Dijon, 2005. 142 p.

\section{Laurent Frajerman}

\section{OpenEdition}

\section{Journals}

\section{Édition électronique}

URL : https://journals.openedition.org/histoire-education/505

DOI : $10.4000 /$ histoire-education.505

ISSN : 2102-5452

\section{Éditeur}

ENS Éditions

\section{Édition imprimée}

Date de publication : 1 avril 2008

Pagination : 159-160

ISBN : 978-2-7342-1117-4

ISSN : 0221-6280

\section{Référence électronique}

Laurent Frajerman, «ATTALI (Michaël), CARITEY (Benoît) (dir.), Le SNEP, une histoire en débat », Histoire de l'éducation [En ligne], 118 | 2008, mis en ligne le 16 octobre 2008, consulté le 20 mai 2021. URL : http://journals.openedition.org/histoire-education/505 ; DOI : https://doi.org/10.4000/histoireeducation.505

Ce document a été généré automatiquement le 20 mai 2021.

(ㄷ) Tous droits réservés 


\section{ATTALI (Michaël), CARITEY (Benoît) (dir.), Le SNEP, une histoire en débat}

Dijon : Éditions universitaires de Dijon, 2005. 142 p.

\section{Laurent Frajerman}

\section{RÉFÉRENCE}

ATTALI (Michaël), CARITEY (Benoît) (dir.), Le SNEP, une histoire en débat, Dijon : Éditions universitaires de Dijon, 2005. 142 p.

1 L'histoire du syndicalisme des professeurs d'éducation physique constitue un souschamp prolifique de l'histoire du syndicalisme, alimenté par des chercheurs issus de la filière "Sciences et techniques des activités physiques et sportives" (STAPS) et par l'existence d'une épreuve vouée à l'histoire de la discipline aux concours de recrutement. Le Syndicat national de l'Éducation physique (SNEP) est le puissant et actif porte-parole d'un corps peu nombreux, qui a longtemps lutté pour abandonner la tutelle du ministère de la Jeunesse et des Sports et être rattaché au ministère de l'Éducation nationale. Combat difficile, du fait d'une mentalité scolaire française qui dévalorise le corps au profit de l'esprit. D'autres syndicats de la Fédération de l'Éducation nationale (FEN), placés dans une position similaire, ont opéré des choix différents: songeons aux professeurs des lycées agricoles, toujours dépendants du ministère de l'Agriculture.

Initiative heureuse, deux spécialistes, Michaël Attali et Benoît Caritey, ont réuni dans cet ouvrage les protagonistes des débats passionnés qui agitent ce milieu. Ce livre constitue une excellente initiation, d'autant qu'il bénéficie d'un travail d'édition soigné, avec des articles bien écrits, une introduction solide, une bibliographie, une chronologie et même un index.

3 Nombre de polémiques sont nourries par l'appartenance, depuis 1969, de la direction du SNEP à la tendance Unité et Action au sein de la FEN, tendance animée notamment par des enseignants communistes. Jean-Luc Martin développe donc la thèse d'une 
inféodation totale du syndicat au parti communiste français (PCF). Son article fleure bon les controverses des années 1960, du fait de son parti pris hostile et de son caractère d'histoire "au sommet ». Un ancien secrétaire général du SNEP, Jacques Rouyer, en réfute, faits précis à l'appui, les éléments les plus contestables : le syndicat défend aussi (ou d'abord ?) ses membres, sinon comment expliquer la progression d'Unité et Action au sein de la FEN ? Notons que Rouyer ne conteste pas l'influence de la culture communiste sur les syndicalistes qui se réclament de ce parti. Plus original, Guilhem Véziers analyse avec pertinence le milieu militant d'Unité et Action et montre l'importance de la formation initiale (le rôle de professeurs communistes à l'École normale supérieure d'Éducation physique) et des conceptions pédagogiques dans la progression de cette tendance au sein du SNEP. Toutefois, le lecteur non spécialiste ne parvient guère à appréhender le contenu des débats pédagogiques, et notamment du « sport éducatif » promu par la majorité syndicale. Michaël Attali montre l'impulsion simultanément pragmatique et combative conférée par Unité et Action au syndicat. Il s'agit de consolider la place de l'éducation physique et sportive comme discipline scolaire, d'obtenir pour elle la création d'un concours d'agrégation, mais aussi de préserver sa spécificité et ses liens avec le monde sportif. Alors que la précédente majorité se situait dans "un rapport de soumission à l'égard de l'institution », le syndicat se veut désormais plus offensif, « tout en intégrant les changements issus des réformes ». Se penchant sur les années 1980, Guy Lapostolle relève que, bien que dirigé par la même tendance que le Syndicat national des enseignants du secondaire (SNES), le SNEP n'envisage pas de fusionner avec lui et s'avère plus proche, sur le plan pédagogique, du Syndicat général de l'Éducation nationale (SGEN-CFDT) et du ministre Alain Savary. Ces positions ne sont pas harmonisées de l'extérieur par le PCF, d'autant que ce parti reste flou sur les arêtes du débat... À une autre échelle, une enquête orale permet à Benoît Caritey de montrer que le SNEP est simultanément facteur d'unité et de division du corps.

4 Ces contributions sont d'un bon niveau, même si l'historiographie plus générale de la Fédération de l'Éducation nationale, à laquelle le SNEP est affilié, n'est que survolée. Des comparaisons utiles manquent, notamment sur la défense des identités professionnelles, cœur des motivations des syndicats enseignants, SNEP compris. Ce livre utile démontre amplement leur importance en accordant une grande place à l'intrication entre les enjeux pédagogiques et corporatifs.

\section{AUTEURS}

\section{LAURENT FRAJERMAN}

